\title{
Theoretical foundations of modeling the process of transport vehicles steel ropes structural defects formation
}

\author{
Anatoly Korotky ${ }^{1}$, Edward Marchenko ${ }^{1}$, Sergey Popov ${ }^{1, *}$, Julianna Marchenko ${ }^{1}$, Nikolai \\ Dontsov $^{1}$ \\ ${ }^{1}$ Don State Technical University, 1, Gagarin sq., 344000, Rostov-on-Don, Russia
}

\begin{abstract}
The article presents materials on the study of mathematical modeling of splicing (binding) of steel rope used to transmit traction by friction. The developed mathematical model splicing (binding) describes the stress-strain state of strands (wires) from quasistatic loads, arising in the cyclic tension process and bending of steel rope on rope sheave, in which the resultant force in steel rope cross section is shifted relative to the central axis, causing it to bend and torsion. Using experimental data, it was found that the steel rope torsion and bending is caused by the linking technology in the nodes where strands are replaced. Experimentally established, that defects on the splicing (binding) site manifested as a result of cyclic tensile and bending loads on rope sheave, which is connected to limited mobility of the strands in nodes due to cross section symmetry violation.
\end{abstract}

\section{Introduction}

In modern machinery, to use high-tech tasks, machines use cable traction. Such machines are characterized by the use of steel ropes of a closed (infinite) type, where the steel rope is a whole closed ring with section formation of its connection (docking), called splicing. Splicing is the method of connecting two ends of the rope, by weaving strands of outer layer into core, with its preliminary removal to a length sufficient for the formation of splicing locks (nodes), filled with strands. Steel ropes splicing process is carried out manually by a certified operator and is standardized according to E28-3 Suspended ropeways "Unified norms and prices for construction, installation and repair-construction works".

Problem setting. In the study of the resource and durability of steel ropes operation, despite high resource of steel ropes declared by the manufacturer $(15-20$ years of exploitation), the authors noted that after $5-6$ years dangerous factors appear at the sites of splicing (breaks, external wear of wires, rope diameter reduction as a result of core damage, loss of internal section, formation of "waviness"), which is the basis for unscheduled rope repair with replacement of the defective area and leads to significant material costs [1-14]. These hazardous factors indicate a violation of the steel rope physicomechanical

\footnotetext{
*Corresponding author: spopov1957@yandex.ru
} 
characteristics at the splicing site and lead to its premature wear.

The physical modeling of steel ropes splicing process allowed the authors to establish the causes of hazardous factors arising on the splicing steel rope site [15-22]. For the normal operation of the steel rope, it is necessary that the resultant load was equally applied to all wires and strands in the steel rope cross section. However, in the run-off section, the resultant load was displaced relative to the axis by the eccentricity value, therefore, uneven loading of the wires and strands of the steel rope occurs. Irregularity loading appears in knots (locks), since it is impossible to ensure the constancy of the length of each refillable strand with manual descent, during operation, as a result of the total resultant force displacement in the cross section of the rope bow along its length, excessive torque occurs. Refillable strands are in rigidly fixed state and do not provide the required mobility of the strands when it is bent on rope sheave (drum). In the "lock" of the "core-strand-strand" friction pair, the effect of "biting" the braided strands is formed, which during operation leads to the formation of a dangerous "waviness" factor.

\section{Theoretical part}

Consider the physical processes that occur on the site of steel rope splicing (coalescing) during its quasistatic loading during cyclic bending on rope sheave. It was experimentally established that in the rope bending process, the mutual movement of the strands occurs. The strand, based on the core, has longitudinal and angular movement, while maintaining a tangential gap between the strands. The absence of the tangential gap in the splicing (coalescing) cross section unit, and, consequently, lack of the necessary strands ("biting") mobility in the splicing "knot" leads to redistribution of force between the strands, i.e. to eccentric stretching of the steel rope as a whole, which ultimately leads to the "waviness" defect formation. During operation of steel rope, one of its strands in the splicing (coalescing) section at the knots transfers the load to another strand by friction forces. In the mathematical model presented below, the friction forces were neglected, replacing it with a tangential gap having different values in the section cross assembly splicing (coalescing).

For designing the mathematical model of splicing (coalescing), we consider the wellknown calculation scheme for determining the force factors acting in steel rope elements [23-31]. We introduce a coordinate system in each cross section of steel rope element $t, n, a$ (trihedral $-\tau$ ), so the axis $\mathrm{t}$ will be sent tangentially, a $\mathrm{n}$ and $\mathrm{B}$, respectively, along the main normal and binormal to the helical axis of its element. The axis of the element is assumed to pass through the centers of gravity of its cross section (Figure 1).

Using the well-known relations of analytic geometry, through $\alpha$ and $\varphi$, we get the direction cosines between the coordinate systems $\tau$ and $\mathrm{x}, \mathrm{y}, \mathrm{z}$

In order to establish connection between internal forces and external forces applied in a knot (lock) of a steel rope counter, it is necessary to go to the global coordinate system x, y, $\mathrm{z}$ related to its cross section. For these purpose, we use the directional cosines of system and design vector $\mathrm{S}$ from coordinate axes $\mathrm{t}, \mathrm{n}$, and on coordinate axis $\mathrm{x}, \mathrm{y}, \mathrm{z}$, we obtain:

$$
\begin{gathered}
S_{x_{i}}=S_{t_{i}} * \cos \alpha+S_{a_{i}} * \sin \alpha \\
S_{y_{i}}=S_{t_{i}} * \sin \alpha * \cos \varphi_{i}+S_{n_{i}} * \sin \varphi-S_{a_{i}} * \cos \alpha * \cos \varphi_{i} \\
S_{z_{i}}=S_{t_{i}} * \sin \alpha * \sin \varphi_{i}+S_{n_{i}} * \cos \varphi+S_{a_{i}} * \cos \alpha * \sin \varphi_{i}
\end{gathered}
$$

Given expression (1), the projections of internal forces on the $\mathrm{x}, \mathrm{y}, \mathrm{z}$ coordinate axes are written as; 


$$
\begin{gathered}
Q_{x_{i}}=F_{t_{i}} * \cos \alpha+F_{a_{i}} * \sin \alpha+r_{i}\left(S_{t_{i}} * \sin \alpha-S_{a_{i}} * \cos \alpha\right) \\
Q_{y 1}=F_{t_{i}} * \sin \alpha * \cos \varphi_{i}+F_{n_{i}} * \sin \varphi_{1}-F_{a_{i}} \cos \alpha * \cos \varphi_{i}-\left(S_{t_{i}} * \cos \alpha+S_{a_{i}} *\right. \\
\sin \alpha) r_{i} * \cos \varphi_{i} \\
Q_{z_{i}}=F_{t_{i}} * \sin \alpha * \sin \varphi_{i}+F_{n_{i}} * \\
\cos \varphi_{i}+F_{a_{i}} * \cos \alpha * \sin \varphi_{i}-\left(S_{t_{i}} * \cos \alpha+S_{a_{i}} *\right. \\
\sin \alpha) r_{i} * \sin \varphi_{i} .
\end{gathered}
$$

where $S_{x_{i}}, S_{y_{i}}, S_{z_{i}}, Q_{x_{i}}, Q_{y_{i}}, Q_{z_{i}}$ - external forces, respectively, relative to the coordinate axes x,y,z; $S_{t_{i}}, S_{n_{i}}, S_{a_{i}}, F_{t_{i}}, F_{n_{i}}, F_{a_{i}}$, - internal forces, respectively, relative to the coordinate axes $\mathrm{t}, \mathrm{a}, \mathrm{n}$;

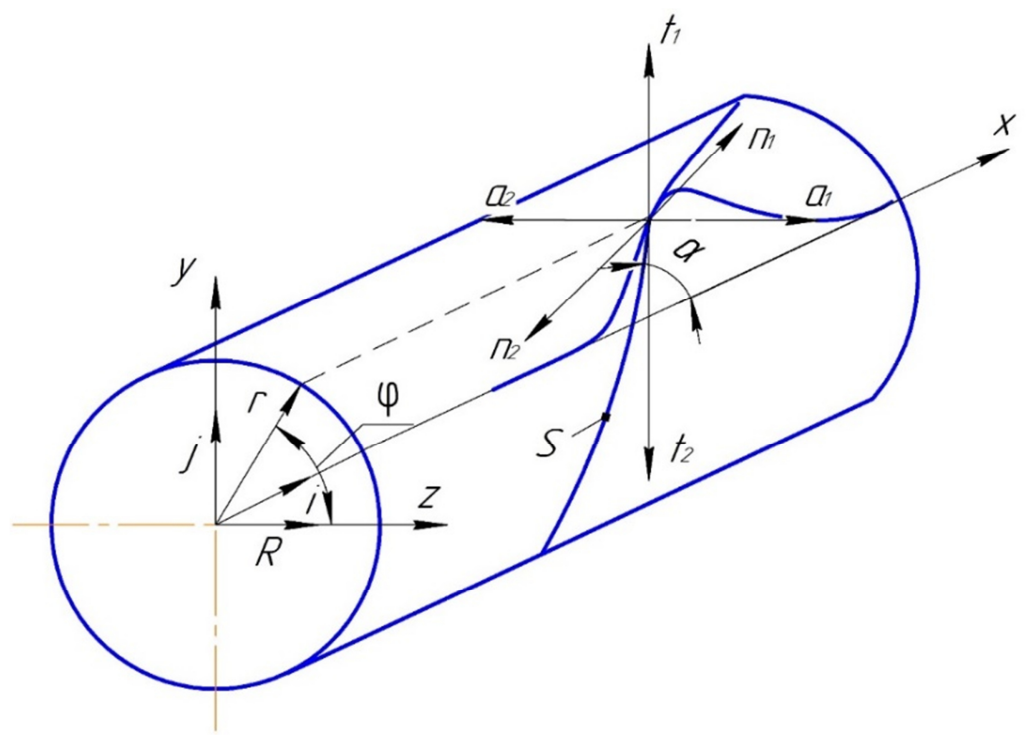

Fig. 1. Coordinate system diagram for calculating force factors acting in the elements of a steel rope.

Let us consider the problem solution in the elastic deformations zone with an external visible absence of "waviness" (Figure 1). Neglecting the radius of curvature of the "waviness" $\rho$, assuming that $\Delta \mathrm{S}_{-}\left(\mathrm{x}_{-} \mathrm{i}\right) \wedge 2=0, \Delta \mathrm{f}_{-}\left(\mathrm{n}_{-} \mathrm{i}\right)=0, \Delta \mathrm{r}_{-} \mathrm{i}=1$, we write the equation in the form:

$$
\begin{gathered}
\Delta S_{t_{i}}=f_{n_{i}} * e \\
\Delta F_{t_{i}}=S_{x_{i}} * e * \sin \alpha-2 f_{n_{i}} * \operatorname{ctg} \alpha * e^{2} \\
\Delta F_{a_{i}}=S_{x_{i}} * e * \cos \alpha+e^{2} * f_{n_{i}}\left(\operatorname{ctg}^{2} \alpha-1\right) .
\end{gathered}
$$

Substituting (3) into (2) we get:

$$
\begin{gathered}
\Delta Q_{\mathrm{k} p}=\sum S_{x_{i}} * e * \sin \alpha * \cos ^{3} \alpha-\sum 2 f_{n_{i}} * \operatorname{ctg} \alpha * e^{2} * \cos ^{3} \alpha+\sum S_{x_{i}} * e * \sin \alpha * \\
\cos \alpha\left(1+\cos ^{2} \alpha\right)+e^{2} \sum f_{n_{i}}\left(\operatorname{ctg}^{2} \alpha-1\right) * \sin \alpha\left(1+\cos ^{2} \alpha\right)
\end{gathered}
$$

Assuming that 


$$
\begin{gathered}
\sum S_{x_{i}}=S_{x} \\
\sum f_{n_{i}}=0
\end{gathered}
$$

then (19) write with (20) and (21)

$$
\Delta Q_{\mathrm{w}}=S_{x} * e * \sin \alpha * \cos \varphi\left(2 \cos ^{2} \alpha+1\right)
$$

Thus, during each operation loading operation, including tension and bending on rope sheave, steel rope must undergo torsional strains caused by the presence of eccentricity e.

Torsion of a steel rope at the splicing (coalescing) site caused by a geometric change in cross section tangential gaps between strands in the knots (locks) provided by its technology. The load between the strands is distributed extremely irregulary, which, ultimately, leads to its eccentric loading of the steel rope. Physical location of steel rope strands in the knots leads to additional loads, which during operation cause cyclic torsion, regular additional stresses in wires (strands) and, as a result, the steel rope bending relative to the central axis.

If the eccentricity is insignificant (plastic deformation is not observed in the elements), then the steel rope torsion leads to the axial force alignment ( $\mathrm{S}_{-}\left(\mathrm{x}_{-} \mathrm{i}\right)$ ) in its elements (strands). In this case, the longitudinal forces $\left(S_{t_{i}}\right)$ in geometrically equivalent steel rope elements, for each loading cycle it do not vary equally. Some of the elements (strands) became overloaded, while others are underloaded. The described process of elements (strands) interaction in the area where the steel ropes are knocked together is one of the reasons for premature rejection due to fatigue failure of individual wires.

The eccentric application of the steel rope cross section load in violation of merging technology can lead to strands plastic deformation. During plastic deformation, steel rope takes the form of helix, characterized by rejection rate - "waviness". It is possible to determine the curvature of "waviness" indirectly, using experimental data and analytical expressions.

As it is known, helix is characterized by radius of twist $\tau$ and by the helical axis tilt angle $\gamma$. The torsion and curvature of the "waviness" helix can be written:

$$
\begin{gathered}
K=\frac{\sin ^{2} \gamma}{r_{b}} \\
\tau=\frac{\sin \gamma * \cos \gamma}{r_{b}} \\
\sin \gamma=\frac{\operatorname{tg} \gamma}{\sqrt{1+\operatorname{tg}^{2} \gamma}} \\
\cos \gamma=\frac{1}{\sqrt{1+\operatorname{tg}^{2} \gamma}}
\end{gathered}
$$

we get:

$$
\operatorname{tg} \gamma=\frac{K}{\tau}
$$




$$
r_{b}=\frac{K}{\tau^{2}+K^{2}}
$$

Let us determine the "waviness" parameters in the splicing (coalescing) section analytically. Knowing the actual loads on the steel rope and its gaps geometric parameters in the assembly cross section associated with the technology design features.

Taking into account that the curvature $\mathrm{K}$ and torsion $\tau$ of the undulation are determined by the expressions:

$$
\begin{gathered}
K=\frac{1}{\rho_{0}+\left(\Delta_{3} / \Delta\right) * S_{x} * r_{b_{0}}} \\
\tau=\frac{\sin \alpha * \cos \alpha}{r_{b_{0}}}+\Delta_{2} / \Delta * S_{x} * r_{b_{0}}
\end{gathered}
$$

where $\frac{1}{\rho_{0}}$ - initial curvature; $r_{b_{0}}$ - initial defective area radius value; $\Delta, \Delta 2, \Delta 3$ determinants of steel rope aggregate stiffness coefficients, determined by (9). Substituting (10) and (9) into (8) we get:

$$
\begin{gathered}
r_{b}=\frac{\frac{1}{\rho_{0}+\left(\Delta_{3} / \Delta\right) * S_{x} * r_{b_{0}}}}{\left(\frac{\sin \alpha * \cos \alpha}{r_{b_{0}}}+\Delta_{2} / S_{x} * r_{b_{0}}\right)^{2}+\left(\frac{1}{\rho_{0}+\left(\Delta_{3} / \Delta\right) * S_{x} * r_{b_{0}}}\right)^{2}} \\
\operatorname{tg}=\frac{\frac{1}{\rho_{0}+\left(\Delta_{3} / \Delta\right) * S_{x} * r_{b_{0}}}}{\frac{\sin \alpha * \cos \alpha}{r_{b_{0}}}+\Delta_{2} / S_{x} * r_{b_{0}}}
\end{gathered}
$$

The additional tensile stresses for the strands located on the spiral steel rope undulation portion are determined by the formula:

$$
\sigma_{s}=E / \Delta_{\Delta} * S_{x} * r_{b}\left(\Delta_{1} * \cos ^{2} \alpha+\Delta_{2} * r * \sin \alpha * \cos \alpha+\Delta_{3} * r * \cos ^{2} \alpha\right) * \cos \varphi
$$

for double strand steel rope:

$$
\begin{gathered}
\sigma_{s}=E / \Delta * S_{x} * r_{b}\left(\Delta_{1} * \cos ^{2} \alpha+\cos ^{2} \beta+\Delta_{2} * r_{k}\left(\sin \beta * \cos \beta+r / r_{k} * \operatorname{tg} \alpha *\right.\right. \\
\left.\left.\cos ^{4} \beta\right)+\Delta_{3} * r_{k} * \cos ^{2} \beta\right)
\end{gathered}
$$

here $\mathrm{E}$ - elastic modulus of the first kind; $\mathrm{Sx}$ - tensile load; $\mathrm{rb}$ - defective area radius; $r$, rk - the radii of the strand and the rope, respectively; $\alpha, \beta$ - twisting angles of wires in strands and rope strands, respectively; $\varphi$ - polar angle.

From the point of view of assessing the safe steel ropes operation, according to the rejection indicators in splicing (coalescing) places, it is of interest to determine the permissible value of waviness radius, based on the most loaded wire strength condition. The total voltage in the hoisting rope elements, taking into account the geometrical parameters in the nodes of the counters, we define by the formula:

$$
\sigma=\sigma_{0}+\sigma_{s} \leq \sigma_{b} / n_{\mathrm{pcs}}
$$


where $\sigma_{0}$ - average stress in the wires of one layer from the action of tensile force $\mathrm{Sx} ; \mathrm{n}$ pcs - the most loaded wire safety margin; $\sigma_{s}-\mathrm{d}$ additional stress caused by "waviness" defect.

Solving expression (16) taking into account (15) and (14) relative to the steel rope splicing (coalescing) section with different tangential gap values in the knot section, expressed in terms of the waviness radius we get:

$$
\frac{d_{b}}{d_{k}} \leq d_{k}+\frac{r_{b}}{r_{k}} \leq 1+\frac{\sigma_{b} / n_{\mathrm{pcs}}-\sigma_{0}}{K_{u} * S_{x} * r_{k}}
$$

where $\mathrm{db}$ - wavy spiral diameter (Figure 2): $\mathrm{dk}$ - rope diameter without defect; $\mathrm{Ku}-$ generalized stiffness coefficient, taking into account the design features of single lay steel rope:

$$
K_{u}=E / \Delta^{*}\left(\Delta_{1} * \cos ^{2} \alpha+\Delta_{2} * 2 \sin \alpha * \cos \alpha+\Delta_{\mathrm{c}} * r * \cos ^{2} \alpha\right)
$$

double lay:

$$
\begin{gathered}
K_{u}=E / \Delta_{\Delta} *\left(\Delta_{1}\right. \\
* \cos ^{2} \alpha+\cos ^{2} \beta+\Delta_{2} * r_{k}\left(\sin \beta * \cos \beta+r / r_{k} * \operatorname{tg} \alpha * \cos ^{4} \beta\right) \\
\left.+\Delta_{\mathrm{c}} * r_{k} * \cos ^{2} \beta\right)
\end{gathered}
$$

\section{Results}

Expression (19) makes it possible to evaluate the steel rope bearing capacity taking into account the detected "waviness" defect in the splicing (coalescing) section.

The studies which were carried out made it possible to establish the criteria for rejection indicators of "waviness" in the area of steel ropes splicing (coalescing) by residual deformations.

It was established that at the splicing (coalescing) site, the steel rope is subject to rejection in the presence of undulation with the ratio $\mathrm{db} / \mathrm{d}>1.33$. Waviness is a type of steel rope deformation, in which its longitudinal axis takes the form of a helical spiral with pitch $\mathrm{Hb}$ and diameter $\mathrm{db}$.

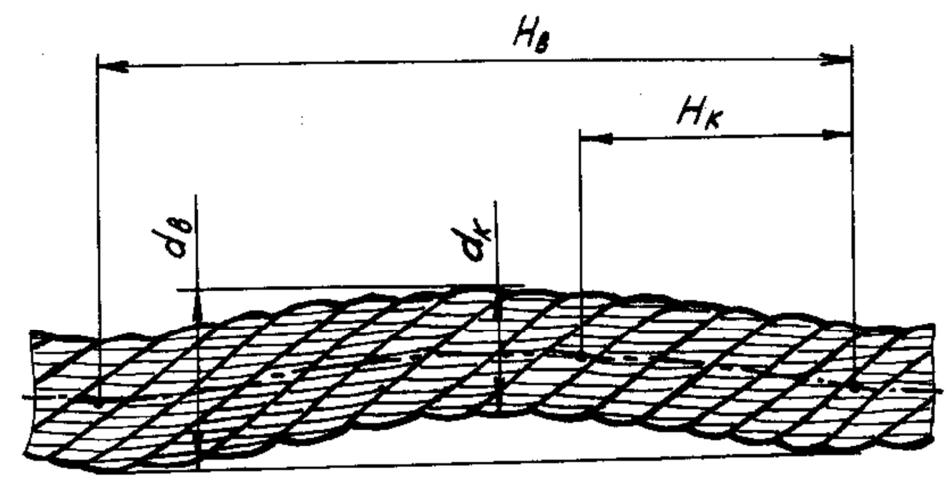

Fig. 2. Defective rope section.

The most dangerous is the undulation, the direction of the spiral of which coincides with steel rope twist direction, while spiral steps of undulation $\mathrm{Hb}$ and the twist $\mathrm{H}$ are the same. The steel rope in the splicing (coalescing) section in the cross section of the nodes loses 
geometric symmetry. In the cross section of the nodes are seven strands, one of which replaces the core. In the cross section of the node, the strands of steel rope are loaded differently: the strands that do not have breaks are overloaded and one of the strands that is replaced by another is underloaded [1-7].

\section{References}

1. V.V. Ivanov, S.I. Popov, E.M. Selemeneva, N.T. Babazhanov, AIP Conference Proceedings 2188, 020015 (2019) doi.org/10.1063/1.5138389

2. V.V. Ivanov, S.I. Popov, Ju.V. Marchenko, E.V. Marchenko, N.S. Dontsov, S.A. Timofeev, IOP Conference Series: Earth and Environmental Science 403, 012115 (2019) doi:10.1088/1755-1315/403/1/012115

3. A.A. Korotky, E.V. Marchenko, V.V. Ivanov, S.I. Popov, Ju.V. Marchenko, N.S. Dontsov, IOP Conference Series: Earth and Environmental Science 403, 012116 (2019) doi:10.1088/1755-1315/403/1/012116

4. A.A. Kotesova, S.V. Teplyakova, S.I. Popov, F.C. Kopylov, IOP Conference Series: Materials Science and Engineering 698, 066029 (2019) doi:10.1088/1757899X/698/6/066029

5. V.V. Ivanov, S.I. Popov, A.V. Kirichek, IOP Conference Series: Materials Science and Engineering 327, 032026 (2018) doi:10.1088/1757-899X/327/3/032026

6. V.V. Ivanov, N.S. Dontsov, A.V. Kirichek, IOP Conference Series: Materials Science and Engineering 327, 032025 (2018) doi:10.1088/1757-899X/327/3/032025

7. V.V. Ivanov, N.P. Pogorelov, N.S. Dontsov, Y.N. Denisenko, AIP Conference Proceedings 2188, 020005 (2019) doi.org/10.1063/1.5138379

8. D. Evseev, A. Kotesova, V. Kosenko, A. Golubeva, IOP Conference Series: Materials Science and Engineering 698, 066032 (2019)

9. V. Kasyanov, V. Deryushev, L. Shulkin, E. Kosenko, A. Kotesova, MATEC Web Conf. 224, 02107 (2018) doi.org/10.1051/matecconf/201822402107

10. V. Deryushev, M. Zaitseva, G. Megera, A. Fedyanov, IOP Conference Series: Materials Science and Engineering 698, 066031 (2019)

11. T. Rogovenko, M. Zaitseva, Materials Science Forum 931, 417-421 (2018) doi.org/10.4028/www.scientific.net/MSF.931.417

12. T. Rogovenko, M. Zaitseva, MATEC Web of Conference 106, 08011 (2017) doi.org/10.1051/matecconf/201610608011

13. T. Rogovenko, M. Zaitseva, MATEC Web of Conferences 129, 05014 (2017) doi.org/10.1051/matecconf/201712905014

14. N.N. Nikolaev, Yu.V. Marchenko, S.K. Filatov, IOP Conference Series: Materials Science and Engineering 698, 066027 (2019) doi:10.1088/1757-899X/698/6/066027

15. V. Ilyasov, B. Meshi, D. Pham, C. Nguyen, O. Holodova, T. Zhdanova, I. Ershov, N. Prutsakova, I. Popova, Springer Proceedings in Physics 207, 127-144 (2018) doi:10.1007/978-3-319-78919-4

16. A. Khoroshev, A. Pavlenko, A. Korotky, D. Tchout, V. Puzin, E. Khorosheva, IOP Conference Series: Materials Science and Engineering 177(1), 012072 (2017) doi:10.1088/1757-89 012072

17. V.A. Lebedev, V.V. Ivanov, V.P. Fedorov, Materials Science and Engineering 124 (2016) doi.10.1088 / 1757-899X / 124/1/012160. R.1-6 
18. V.P. Smolentsev, A.I. Portnykh, V.V. Ivanov, IOP Conf. Series: Materials Science and Engineering 327, 042121 (2018) doi: 10.1088 / 1757-899X / 327/4/042121

19. S.I. Kambulov, I.V. Bozhko, A.V. Olshevskaya, MATEC Web of Conferences 224, 05022 (2018) https://doi.org/10.1051/matecconf/201822405022

20. Yu.A. Ivanov, V.I. Pakhomov, S.I. Kambulov, D.V. Rudoi, MATEC Web of Conferences 224, 05023 (2018) https://doi.org/10.1051/matecconf/201822405023

21. A. Altybayev, A. Zhanbyrbayev, B. Meskhi, D. Rudoy, A. Olshevskaya, A. Prohorova, E3S Web of Conferences 135, $01078 \quad$ (2019) https://doi.org/10.1051/e3sconf/201913501078

22. B. Meskhi, B. Golev, V. Efros, D. Rudoy, A. Olshevskaya, V. Zhurba, Y. Chayka, E3S Web of Conferences 135, 01083 (2019) https://doi.org/10.1051/e3sconf/201913501083

23. J. Gerber, A. Zavaly, A. Gavrilov, A. Olshevskaya, N. Kiyan, IOP Conf. Series: Earth and Environmental Science 403, 012014 (2019) doi:10.1088/1755-1315/403/1/012014

24. G. Parkhomenko, S. Kambulov, A. Olshevskaya, A. Babadzhanyan, N. Gucheva, I. Mekhantseva, IOP Conf. Series: Earth and Environmental Science 403, 012144 (2019) doi:10.1088/1755-1315/403/1/012144

25. Y. Lachuga, A. Soloviev, A. Matrosov, I. Panfilov, V. Pakhomov, D. Rudoy, IOP Conf. Series: Earth and Environmental Science 403, 012055 (2019) doi:10.1088/17551315/403/1/012055

26. E. Zubrilina, I. Markvo, V. Novikov, A. Beskopylny, L. Vysochkina, D. Rudoy, A. Butovchenko, IOP Conf. Series: Earth and Environmental Science 403, 012063 (2019) doi:10.1088/1755-1315/403/1/012063

27. A.A. Kostoglotov, D.S. Andrashitov, A.S. Kornev, S.V. Lazarenko, Measurement Techniques 62, 497-502 (2019) DOI: 10.1007/s11018-019-01652-8

28. S.V. Lazarenko, A.A. Kostoglotov, Journal of Communications Technology and Electronics 62(2), 123-127 (2017) DOI: 10.1134/S1064226917020061

29. A.A. Kostoglotov, I.V. Pugachev, S.V. Lazarenko, AIP Conference Proceedings (2019) DOI: $10.1063 / 1.5138398$

30. A.A. Kostoglotov, I.V. Pugachev, A.A. Yachmenov, S.V. Lazarenko, Advances in Intelligent Systems and Computing 874, 116-124 (2019) DOI: 10.1007/978-3-03001818-4_12

31. S.V. Lazarenko, A.A. Kostoglotov, A.I. Kostoglotov, Journal of Communications Technology and Electronics 54(4), 431-438 (2009) DOI: $10.1134 / \mathrm{S} 1064226909040081$ 